\title{
PERFORMANCE MEASUREMENT AND DYNAMIC ANALYSIS OF TWO DOF ROBOTIC ARM MANIPULATOR
}

\author{
Y. D. Patel ${ }^{1}$, P. M. George ${ }^{2}$ \\ ${ }^{1}$ Associate Professor, Department of Mechanical Engineering, A. D. Patel Institute of Technology, New Vallabh \\ Vidyanagar, Gujarat, India, yash523@rediffmail.com \\ ${ }^{2}$ Professor, Department of Mechanical Engineering, Birla Vishvakarma Mahavidyalaya Engineering College, Vallabh \\ Vidyanagar, India,pmgeorge02@yahoo.com
}

\begin{abstract}
Forward and inverse kinematic analysis of 2DOF robot is presented to predict singular configurations. Cosine function is used for servo motor simulation of kinematics and dynamics using Pro/Engineer. The significance of joint-2 for reducing internal singularities is highlighted. Performance analysis in terms of condition number, local conditioning index and mobility index is carried out for the manipulator. Dynamic analysis using Lagrangian's and Newton's Euler approach is worked out analytically using MATLAB and results are plotted for their comparison.
\end{abstract}

Index Terms: Forward kinematics, Inverse Kinematics, Workspace boundary, Singularity, Dynamics

\section{INTRODUCTION}

Automation is an integral part of day to day activities of modern manufacturing organizations throughout the world. Serial as well as parallel robotic manipulators play a wider and significant role for automation in those organizations. Advancement in serial manipulators is lucrative for the researchers either for its better control, singular configurations, optimization of the manipulator parameters or improving workspace. The prime importance in study of robot motion without regard to forces that produce it is still a challenging area for researchers for any type of manipulators. Typically, it is constrained by the geometry of links used for the configuration. Such areas include robot arm workspacepoints cloud of robotic manipulator reach, singularity- a position in the robot's workspace where one or more joints no longer represent independent controlling variables. The equally important aspect of dynamic studies of the manipulator is to understand nature and magnitude of forces acting, singularity avoidance, power requirements as well as optimization criterion. PD control with computed feed forward controller was compared and was found best amongst computed-torque control, PD+ control, PD control with computed feed forward and PD control based on root mean square average performance index by Reyes and Kelly [1]. Artificial Neural Network method as an alternative solution for forward and inverse kinematic mapping was proposed by Jolly Shah, S.S.Rattan, B.C.Nakra [2]. DH Parameter formulation represented using four parameters by Denavit \& Hartenberg (1955) [3], which showed that a general transformation between two joints in a space. The decoupling of dynamic equations eliminates torques due to gravitational, centripetal and coriolis forces [4]. Kinematic and dynamic parameters are analyzed using ANNOVA to imitate the real time performance measurement of 2-DOF planar manipulator [5]. Optimal dynamic balancing is formulated by minimization of the root-mean-square value of the input torque of 2DOF serial manipulator and results are simulated using ADAMS software [6]. The dynamic parameters of 2 DOF are estimated and results are validated through simulation [7]. Non-linear control law for serially arranged n-link is derived using Lyapunov-based theory by M W Sponge [8]. Recently, position control using neuro-fuzzy controller is proposed for 2-DOF serial manipulator [9].

Forward and inverse kinematics, DH parameters formulations and dynamic analysis for 2 DOF robot arm is as under,

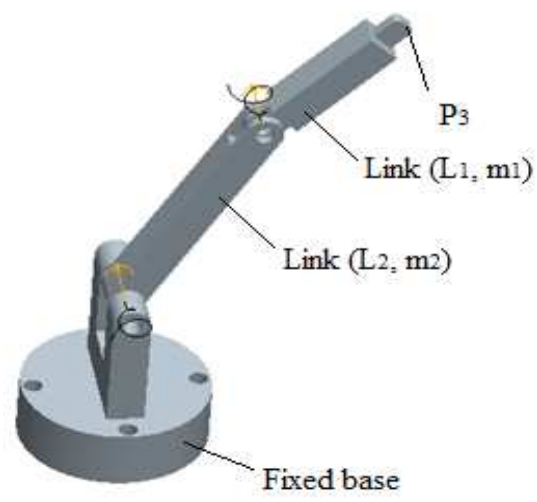

Fig -1: Two DOF planar manipulator 


\section{FORWARD KINEMATICS}

The position and orientation of end effectors is a non linear function of joint variables $P_{3}(x, y)=f(q)$.

$$
\begin{aligned}
& x=L_{1} \cos q_{1}+L_{2} \cos \left(q_{1}+q_{2}\right) \\
& y=L_{1} \sin q_{1}+L_{2} \sin \left(q_{1}+q_{2}\right)
\end{aligned}
$$

Joint ranges are constrained for the manipulator analysis in the present case as,

$$
+90^{\circ} \leq \mathrm{q}_{1} \ll-90^{\circ} \text { and }+45^{\circ} \leq \mathrm{q}_{2} \ll-45^{\circ}
$$

By differentiating the above two expressions,

$$
\begin{aligned}
& \dot{\mathrm{x}}=-\mathrm{L}_{1} \sin \mathrm{q}_{1} \cdot \dot{\mathrm{q}}_{1}-\mathrm{L}_{2} \sin \left(\mathrm{q}_{1}+\mathrm{q}_{2}\right)\left(\dot{\mathrm{q}}_{1}+\dot{\mathrm{q}}_{2}\right) \\
& \dot{\mathrm{y}}=\mathrm{L}_{1} \cos \mathrm{q}_{1} \cdot \dot{\mathrm{q}}_{1}+\mathrm{L}_{2} \cos \left(\mathrm{q}_{1}+\mathrm{q}_{2}\right)\left(\dot{\mathrm{q}}_{1}+\dot{\mathrm{q}}_{2}\right)
\end{aligned}
$$

In matrix form,

$$
\left[\begin{array}{c}
\dot{\mathrm{x}} \\
\dot{\mathrm{y}}
\end{array}\right]=\left[\begin{array}{cc}
-\mathrm{L}_{1} \sin \mathrm{q}_{1}-\mathrm{L}_{2} \sin \left(\mathrm{q}_{1}+\mathrm{q}_{2}\right) & -\mathrm{L}_{2} \sin \left(\mathrm{q}_{1}+\mathrm{q}_{2}\right) \\
\mathrm{L}_{1} \cos \mathrm{q}_{1}+\mathrm{L}_{2} \cos \left(\mathrm{q}_{1}+\mathrm{q}_{2}\right) & \mathrm{L}_{2} \cos \left(\mathrm{q}_{1}+\mathrm{q}_{2}\right)
\end{array}\right]\left[\begin{array}{c}
\dot{\mathrm{q}}_{1} \\
\dot{\mathrm{q}}_{2}
\end{array}\right]
$$

$$
\dot{\mathrm{X}}=\mathrm{J} \cdot \dot{\mathrm{q}}
$$

Where, $\dot{X}$ is the velocity of end effector, $J$ is jacobian matrix and $\dot{\mathrm{q}}$ represents joint rates. For a rotational joint the analytic a geometric jacobian are different. Jacobian matrix represents the relationship between rates of change of pose with respect to joint rates. Rank deficiency of jacobian represents singularity.

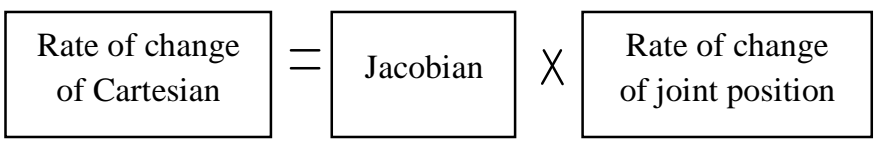

\subsection{DH parameters of 2DOF arm}

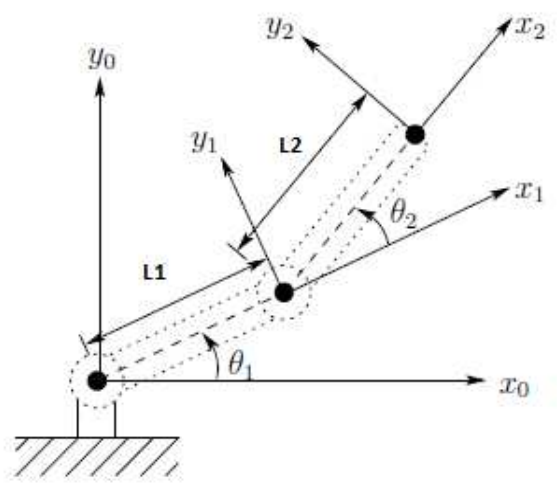

Fig -2: Frame attachment for Two DOF planar manipulator
Table -1: DH Parameters

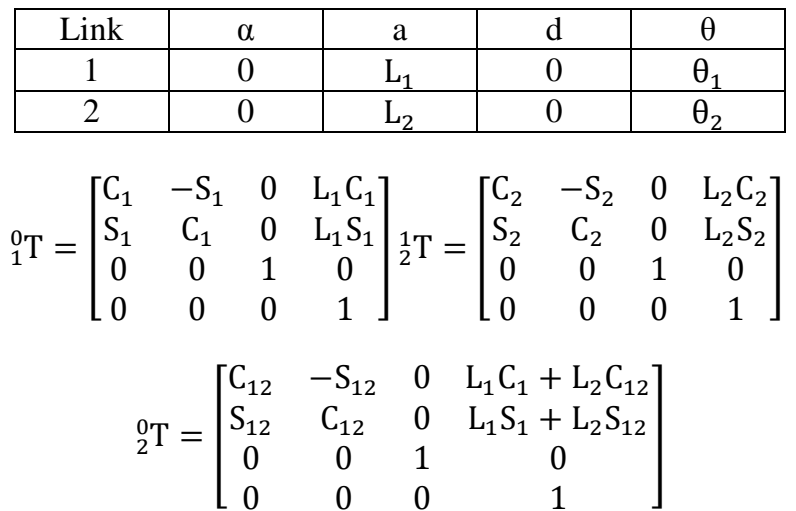

Where,

$\mathrm{L}_{\mathrm{i}}=$ Link length of ith link

$\dot{\theta}_{\mathrm{i}}=$ Joint rates of ith actuator

$\mathrm{C}_{1}=\cos \theta_{1}$

$\mathrm{S}_{1}=\sin \theta_{1}$

$\mathrm{C}_{12}=\cos \left(\theta_{1}+\theta_{2}\right)$

$\mathrm{S}_{12}=\sin \left(\theta_{1}+\theta_{2}\right)$

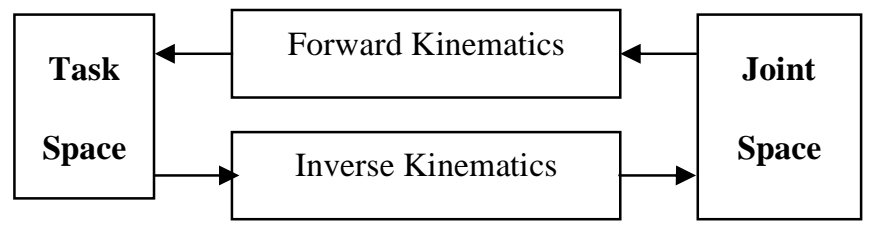

Fig -3: Kinematic Mapping

\section{INVERSE KINEMATICS}

The pose of the robot manipulator $H=\left[\begin{array}{ll}R & P \\ 0 & 1\end{array}\right]$ is known and the joint variables need to be identified for a pose. The geometric solution of the inverse kinematics are summarized in the form of,

$$
\begin{gathered}
\operatorname{cosq}_{2}=\frac{\mathrm{x}^{2}+\mathrm{y}^{2}-\mathrm{L}_{1}{ }^{2}-\mathrm{L}_{2}^{2}}{2 \mathrm{~L}_{1} \mathrm{~L}_{2}} \\
\operatorname{tanq}_{1}=\frac{\mathrm{y}\left(\mathrm{L}_{2} \cos \mathrm{q}_{2}+\mathrm{L}_{1}\right)-\mathrm{x}_{1} \mathrm{~L}_{2} \sin \mathrm{q}_{2}}{\mathrm{x}\left(\mathrm{L}_{1}+\mathrm{L}_{2} \cos \mathrm{q}_{2}\right)+\mathrm{yL}_{2} \sin \mathrm{q}_{2}}
\end{gathered}
$$

Joint velocity and the end-effectors velocity has a velocity constraint and is expressed as,

$$
\begin{gathered}
\dot{\mathrm{q}}=\mathrm{J}^{-1} \dot{\mathrm{X}} \\
\mathrm{J}^{-1}=\left[\begin{array}{cc}
\mathrm{C}_{12} /\left(\mathrm{L}_{1} \mathrm{~S}_{2}\right) & \mathrm{S}_{12} /\left(\mathrm{L}_{1} \mathrm{~S}_{2}\right) \\
-\left(\mathrm{L}_{2} \mathrm{C}_{12}+\mathrm{L}_{1} \mathrm{C}_{1}\right) / \mathrm{L}_{1} \mathrm{~L}_{2} \mathrm{~S}_{2} & -\left(\mathrm{L}_{2} \mathrm{~S}_{12}+\mathrm{L}_{1} \mathrm{~S}_{1}\right) / \mathrm{L}_{1} \mathrm{~L}_{2} \mathrm{~S}_{2}
\end{array}\right]
\end{gathered}
$$


Determinant of inverse jacobian matrix is $-\left(\mathrm{C}_{12} \mathrm{~S}_{1}-\mathrm{S}_{12} \mathrm{C}_{1}\right)$ / $\mathrm{L}_{1} \mathrm{~L}_{2} \mathrm{~S}_{2}{ }^{2}$. If the value of determinant is zero for given task space coordinates then the resulting configuration is singular. Desired pose can be achieved by iterative determination of the joint angles. Multi valued inverse mapping and redundancy are common problems with inverse kinematic.

\section{PERFORMANCE MEASUREMENT}

Manipulability measures the effective robotic pose for object manipulation with in workspace. The term was proposed by Yoshikawa [10] and manipulability index $(\mu)$ is defined as,

$$
\mu=|\operatorname{det}(J)|=\prod_{i=1}^{2} \sigma_{i}
$$

Where, $\mathrm{J}$ is jacobian of robot kinematics. For a two DOF RRrobotic manipulator, the manipulability index is in form of $\mu=L_{1} L_{2}\left|\operatorname{sinq}_{2}\right|$. The manipulability index always varies within the workspace. The normalized mobility index is also an alternative way to represent a singular configuration and determining well conditioned workspace. Its value near to zero near boundaries shows boundary singularities. The condition number is another measure of presence of singularity as well as dexterity of robotic pose. Normally, the larger value of condition number above 30 indicates presence of singularity. The condition number is representation of an amplification factor of error during actuation. It is used for optimum trajectory planning and gross motion calculation of robotic manipulation within workspace. It ranges from $1 \leq \kappa \leq \infty$. Hence, the local conditioning index also known as reciprocal of condition number is used to determine control accuracy, dexterity and isotropy of manipulator. Figure 4(a) and 4(b) shows the variation of mobility index and condition number within workspace for $\mathrm{l}_{1}=0.2 \mathrm{~m}$ and $\mathrm{l}_{2}=0.15 \mathrm{~m}$ without time lag between servomotors with cosine input using MATLAB program respectively. The position curve is also plotted in same figure as shown on xy-plane for specified joint ranges.

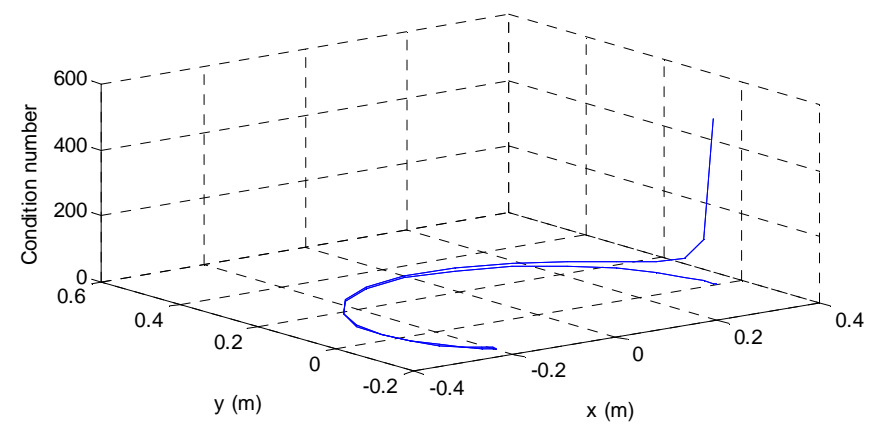

Fig -4 (a): Variation of condition number

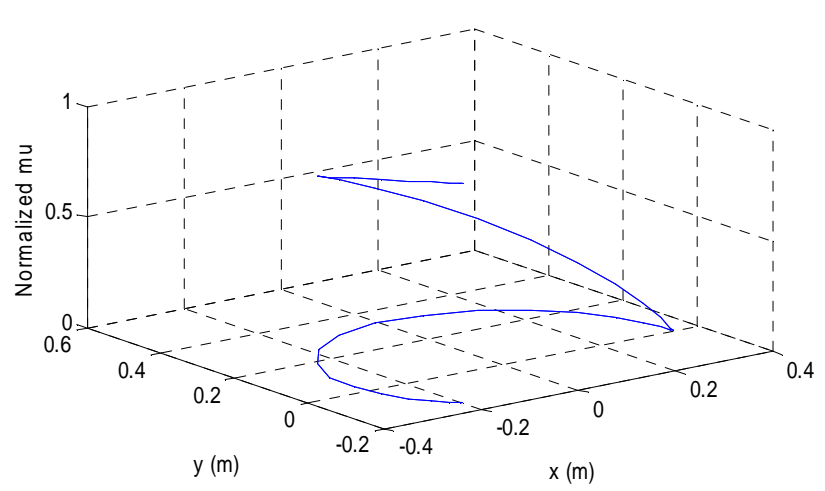

Fig -4 (b): Mobility Index $\mu$

Moreover, jacobian matrix loses its rank then the corresponding robot configurations are termed as singular configurations. It means for the smaller movements in operational space large amount of velocities are required at joints.
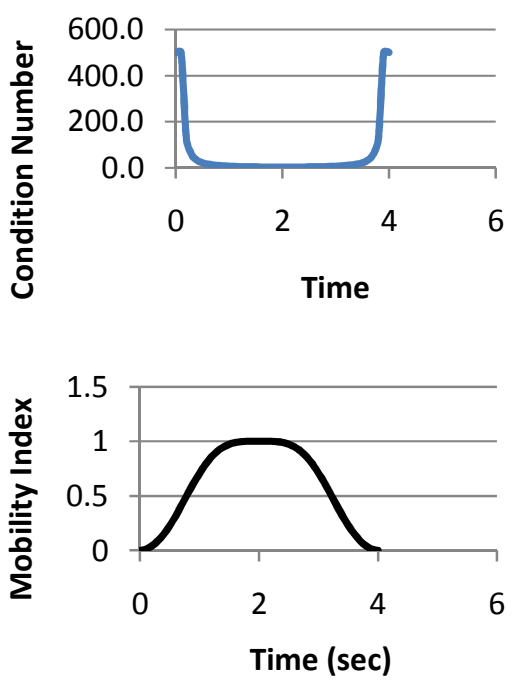

Fig -5: Variation of condition number and mobility index with respect to time

$\mathrm{q}=\mathrm{A} * \cos \left(360 * \frac{\mathrm{x}}{\mathrm{T}}+\mathrm{B}\right)+\mathrm{C}$ is called a general cosine function, which is used as an input to the both servo motors simulation for kinematic and dynamic analysis. In the expression $\mathrm{A}, \mathrm{B}, \mathrm{C}$ and $\mathrm{T}$ affects amplitude, phase, offset (horizontal translation) and period (vertical translation) respectively. 


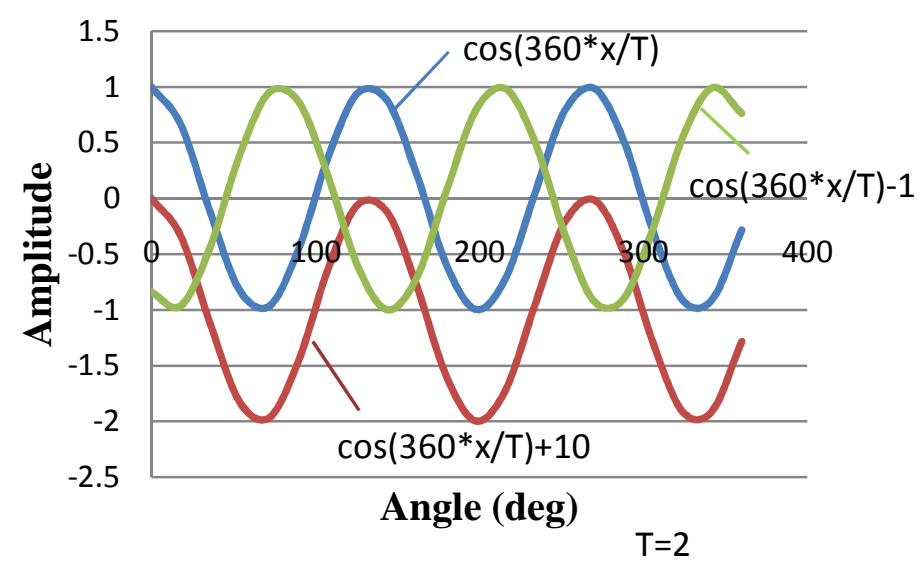

Fig -6: Cosine function with horizontal and vertical offset

\section{DYNAMIC ANALYSIS}

The dynamic behavior of manipulator is described in terms of the time rate of change of the robot configuration in relation to the joint torques exerted by the actuators. Hence, the resulting equation of motions represents such relationship in form of set of differential equations that govern the dynamic response of the robot linkage to input joint torques. Dynamic model for two DOF robot using Newton's Euler approach, the dynamic equations are written separately for each link. Equations are evaluated in numeric or recursive manner. In this case, the sum of forces is equal to variation of linear momentum. The joint torques $\tau_{1}$ and $\tau_{2}$ are coupling moments.

$$
M(q) . \ddot{q}+C(q, \ddot{q}) \cdot \dot{q}+g(q)+f(\dot{q})=\tau_{L}
$$

Where,

$\mathrm{q}=$ Joint displacements

$\dot{\mathrm{q}}=$ Joint velocities

$\ddot{\mathrm{q}}=$ Joint accelerations

$\mathrm{M}(\mathrm{q})=$ Manipulator inertia matrix

$C(q, \ddot{q})=$ Matrix of centripetal \& coriolis torques

$\mathrm{g}(\mathrm{q})=$ Gravitational torques

$\mathrm{f}(\dot{\mathrm{q}})=$ Friction torques

$\tau_{\mathrm{L}}=$ Applied torque inputs

For a two degree of freedom manipulator,

$\left[\begin{array}{l}\tau_{1} \\ \tau_{2}\end{array}\right]=\left[\begin{array}{ll}i_{11} & i_{12} \\ i_{21} & i_{22}\end{array}\right]\left[\begin{array}{l}x_{3} \\ x_{6}\end{array}\right]+\left[\begin{array}{ll}c_{11} & c_{12} \\ c_{21} & c_{22}\end{array}\right]\left[\begin{array}{l}x_{2} \\ x_{5}\end{array}\right]+\left[\begin{array}{l}g_{11} \\ g_{21}\end{array}\right]\left[x_{1}\right]$

Where,

$$
\begin{array}{ll}
\ddot{\mathrm{q}_{1}}=\mathrm{x}_{3} & \ddot{\mathrm{q}_{2}}=\mathrm{x}_{6} \\
\dot{\mathrm{q}}_{1}=\mathrm{x}_{2} & \dot{\mathrm{q}}_{2}=\mathrm{x}_{5} \\
\mathrm{q}_{1}=\mathrm{x}_{1} & \mathrm{q}_{2}=\mathrm{x}_{4}
\end{array}
$$

The above equation can be rearranged in the form of,

$$
\left[\begin{array}{l}
\tau_{1} \\
\tau_{2}
\end{array}\right]=\left[\begin{array}{llllll}
g_{11} & c_{11} & i_{11} & 0 & c_{12} & i_{12} \\
g_{21} & c_{21} & i_{21} & 0 & c_{22} & i_{22}
\end{array}\right]\left[\begin{array}{l}
x_{1} \\
x_{2} \\
x_{3} \\
x_{4} \\
x_{5} \\
x_{6}
\end{array}\right]
$$

The inertia matrix of 2 DOF robot arm is symmetric and positive definite and its elements are,

$\left[\begin{array}{ll}i_{11} & i_{12} \\ i_{21} & i_{22}\end{array}\right]$

Where,

$$
\begin{aligned}
& \mathrm{i}_{11}=\mathrm{m}_{1} \mathrm{a}_{\mathrm{c1}}{ }^{2}+\mathrm{m}_{2}\left(\mathrm{a}_{1}{ }^{2}+\mathrm{a}_{\mathrm{c} 2}{ }^{2}+2 \mathrm{a}_{1} \mathrm{a}_{\mathrm{c} 2} \mathrm{C}_{2}\right)+\mathrm{I}_{1}+\mathrm{I}_{2} \\
& \mathrm{i}_{12}=\mathrm{m}_{2}\left(\mathrm{a}_{\mathrm{c} 2}{ }^{2}+\mathrm{a}_{1} \mathrm{a}_{\mathrm{c} 2} \mathrm{C}_{2}\right)+\mathrm{I}_{2} \\
& \mathrm{i}_{21}=\mathrm{m}_{2}\left(\mathrm{a}_{\mathrm{c} 2}{ }^{2}+\mathrm{a}_{1} \mathrm{a}_{\mathrm{c} 2} \mathrm{C}_{2}\right)+\mathrm{I}_{2} \\
& \mathrm{i}_{22}=\mathrm{m}_{2} \mathrm{a}_{\mathrm{c} 2}{ }^{2}+\mathrm{I}_{2}
\end{aligned}
$$

The inertia has maximum value for fully extended arm. The elements of centripetal and coriolis matrix,

$$
\left[\begin{array}{ll}
c_{11} & c_{12} \\
c_{21} & c_{22}
\end{array}\right]=\left[\begin{array}{cc}
-2 m_{2} a_{1} a_{c 2} S_{2} x_{5} & -m_{2} a_{1} a_{c 2} S_{2} x_{5} \\
m_{2} a_{1} a_{c 2} S_{2} x_{2} & 0
\end{array}\right]
$$

Entries of gravitational terms are,

$$
\left[\begin{array}{l}
g_{11} \\
g_{21}
\end{array}\right]=\left[\begin{array}{c}
m_{1} g a_{c 1} C_{1}+m_{2} g\left(a_{1} C_{1}+a_{c 2} C_{12}\right) \\
m_{2} g a_{c 2} C_{12}
\end{array}\right]
$$

When arm is fully extended in the x-direction, the effect of gravitational moment becomes maximums. The closed form dynamic equations of $n$-degree-of-freedom robot in the form of,

$$
\tau_{i}=\sum_{j+1}^{n} M_{i j} \ddot{q}_{j}+\sum_{\substack{j=1 \\ i=1, \ldots, n}}^{n} \sum_{k=1}^{n} C_{i j k} \dot{q}_{j} \dot{q}_{k}+G_{i}\left(q_{i}\right)+f_{i}\left(\dot{q}_{i}\right),
$$

Lagrangian Euler approach is based on differentiation of energy terms with respect to the systems variable and time. Internal reaction forces are automatically eliminated using this method. Closed form equations are directly obtained. Here, the sum of torques is equal to variation of angular momentum. The total energy stored in each link is represented as,

$$
\tau_{\mathrm{i}}=\sum_{\mathrm{i}=1}^{2}\left(\frac{1}{2} \mathrm{~m}_{\mathrm{i}}\left|\mathrm{V}_{\mathrm{ci}}\right|^{2}+\frac{1}{2} \mathrm{I}_{\mathrm{i}} \omega_{\mathrm{i}}{ }^{2}\right)
$$

The resulting expression as same as obtained using Newton's Euler approach. Lagrangian formulation is simpler than Newton's Euler approach. 


\subsection{Mass Properties of Both Links}

The case of 2-DOF serial manipulator under consideration has following mass properties,

\section{Link1}

Material Properties: steel (AISI 1045)

Poisson's ratio: 0.27 at $25^{\circ} \mathrm{C}$

Young's modulus: $199 \mathrm{GPa}$

Coefficient of thermal expansion: $1.17 \times 10^{-5}$ per ${ }^{\circ} \mathrm{C}$

Density: $7.827 \times 10^{3} \mathrm{~kg} / \mathrm{m} 3$

Length $\mathrm{L}_{1}=0.2 \mathrm{~m}$

Mass $\mathrm{m}_{1}=1.383 \mathrm{~kg}$

\section{Link2}

Material Properties: steel (AISI 1045)

Poisson's ratio: 0.27 at $25^{\circ} \mathrm{C}$

Young's modulus: 199GPa

Coefficient of thermal expansion: $1.17 \times 10^{-5}$ per ${ }^{\circ} \mathrm{C}$

Density: $7.827 \times 10^{3} \mathrm{~kg} / \mathrm{m} 3$

Length $\mathrm{L}_{2}=0.15 \mathrm{~m}$

Mass $\mathrm{m}_{2}=0.82658 \mathrm{~kg}$

Inertia with respect to coordinate system attached at base (tonne. $\mathrm{m} 2$ )

$$
\left[\begin{array}{ccc}
1.234 \times 10^{11} & 0 & 0 \\
0 & 2.0405 \times 10^{10} & 0 \\
0 & 0 & 1.2155 \times 10^{11}
\end{array}\right]
$$

Inertia tensor at centre of gravity with respect to coordinate system (tonne. m2)

$$
\left[\begin{array}{ccc}
2.1817 \times 10^{10} & 0 & 0 \\
0 & 2.0030 \times 10^{10} & 0 \\
0 & 0 & 2.0405 \times 10^{10}
\end{array}\right]
$$

As shown in above table, the inertia tensor for an object with the coordinates of the centroid of the rigid body $\left(\mathrm{x}_{\mathrm{c}}, \mathrm{y}_{\mathrm{c}}, \mathrm{z}_{\mathrm{c}}\right)$ and $\rho$ is mass density, is computed as,

$$
I=\left[\begin{array}{lll}
I_{x x} & I_{x y} & I_{x z} \\
I_{y x} & I_{y y} & I_{y z} \\
I_{z x} & I_{z y} & I_{z z}
\end{array}\right]
$$

Each element represents scalar quantity expressing resistance changes with respect to change of rotation of an object. Hence, the value of inertia tensor components varies with respect to time. The three diagonal elements are called principal moment of inertia and six off diagonal elements are called cross product of inertia.

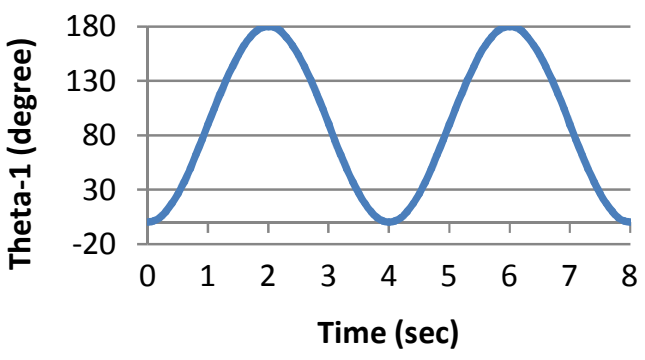

(a)Variation of $\theta_{1}$ with time

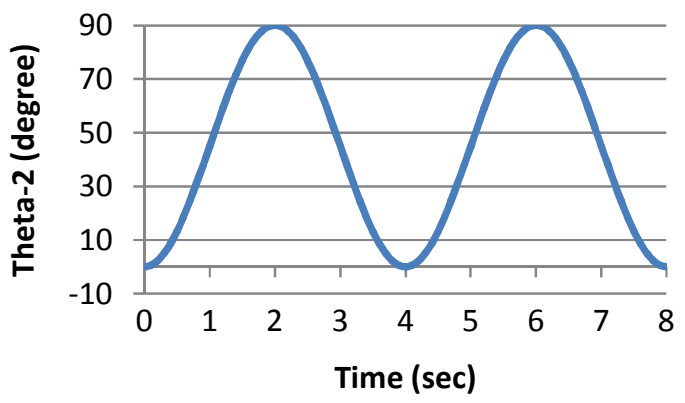

(b) Variation of $\theta_{2}$ with time

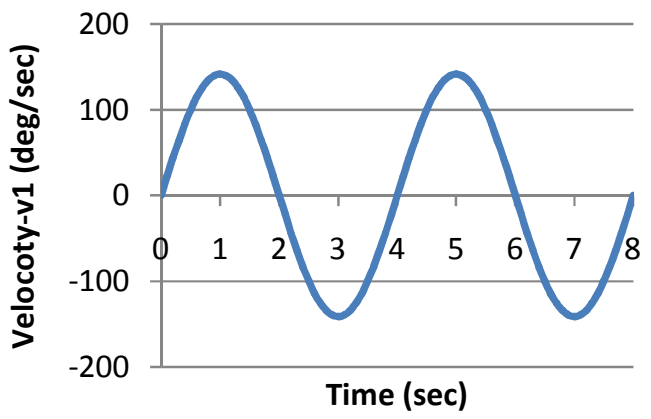

(c) Variation of velocity $v_{1}$ with time

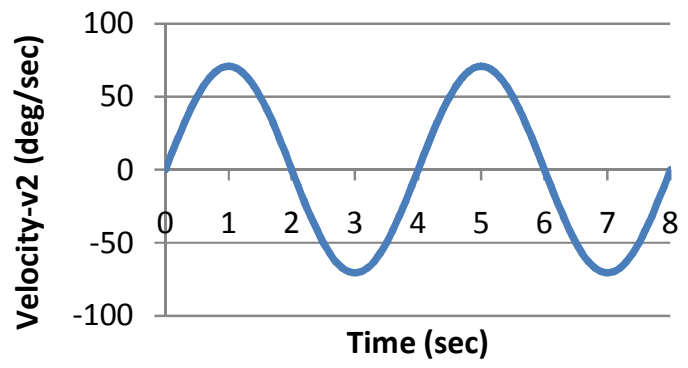

(d) Variation of velocity $v_{2}$ with time 


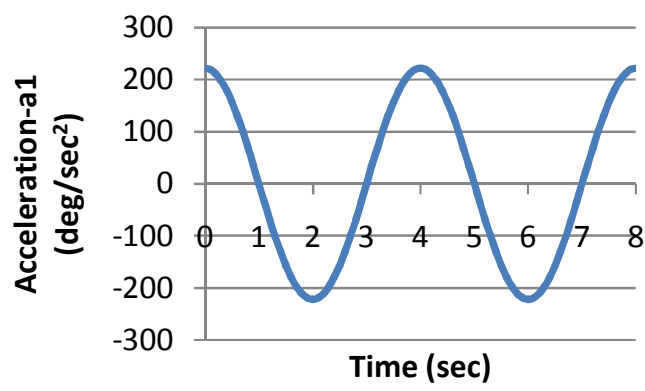

(e) Variation of acceleration $\mathrm{a}_{1}$ with time

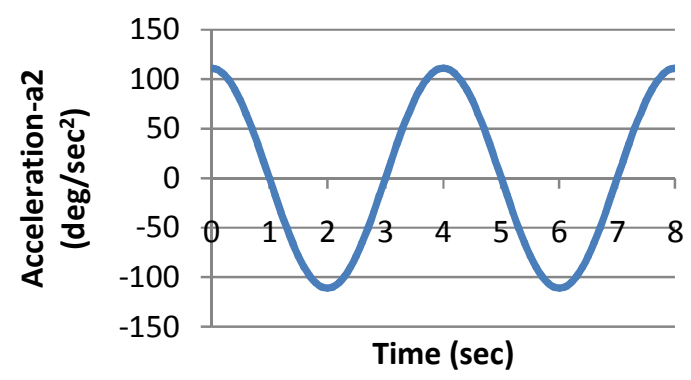

(f) Variation of acceleration $\mathrm{a}_{2}$ with time

Fig -7: Variation of q, $\dot{q}$ and $\ddot{q}$ of joint-1 and joint-2 with respect to time

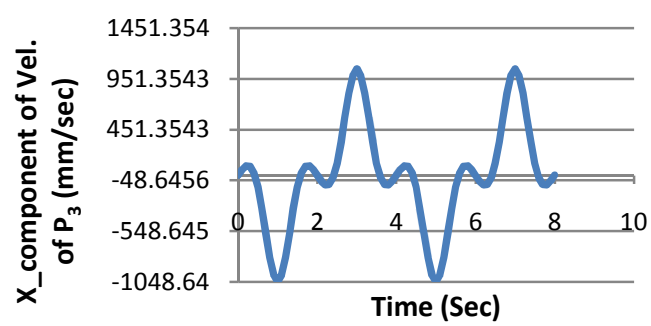

(g) Variation of X_comp. of vel. of P3 with time

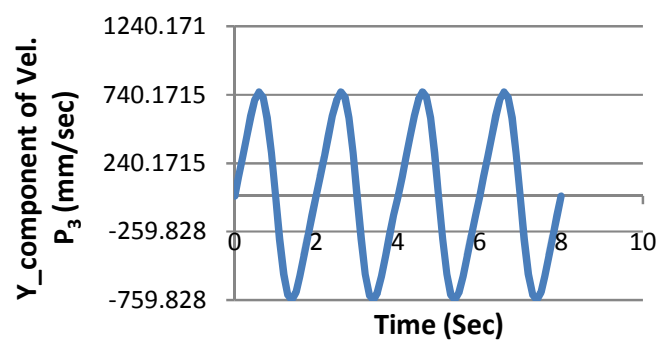

(h) Variation of X_comp. of vel. of P3 with time

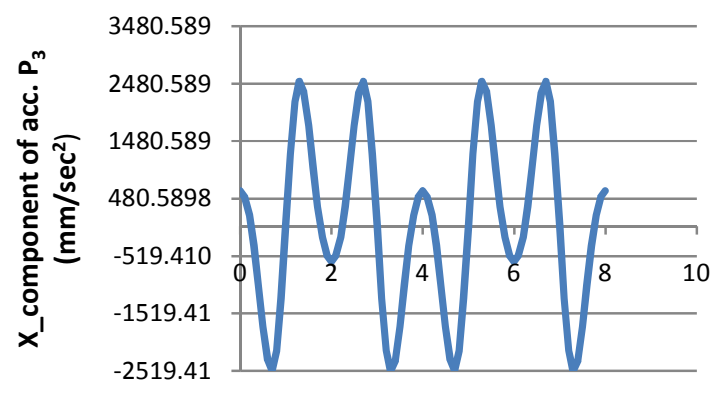

Time (Sec)

(i) Variation of X_comp. of acc. of P3 with time

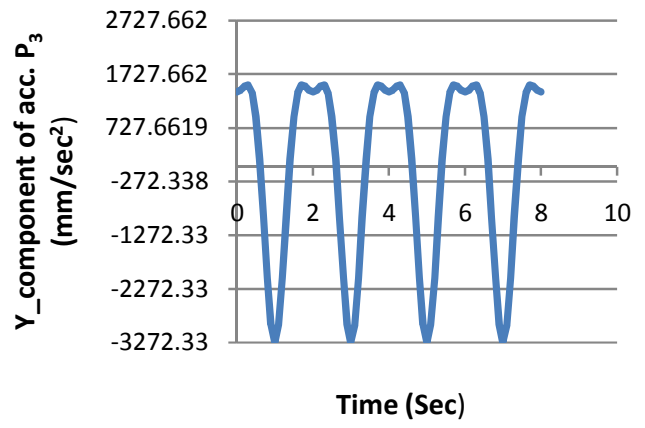

(j) Variation of Y_comp. of acc. of P3 with time

Fig -8: Variation of velocity and acceleration of point $\mathrm{P}_{3}$ with respect to time
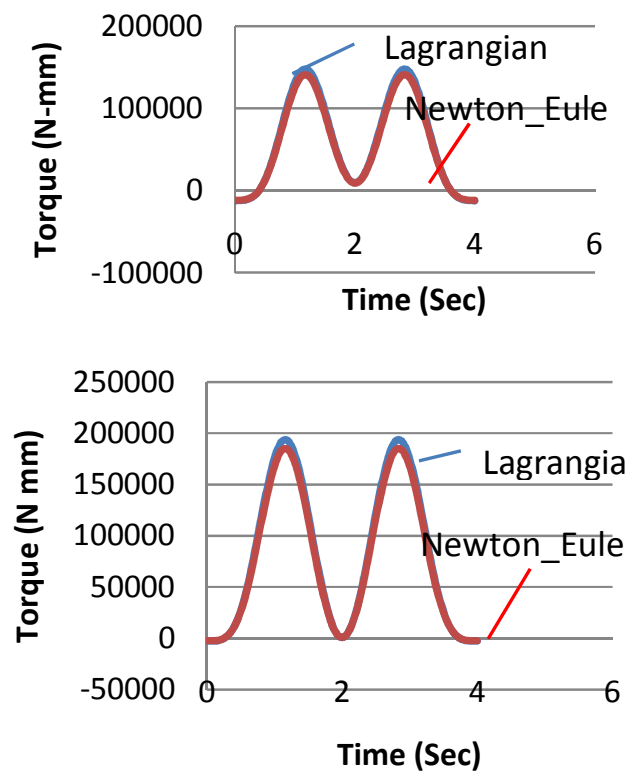

Fig -9: Torque requirements at joint-1 and joint-2 with respect to time 


\section{WORKSPACE BOUNDARY:}

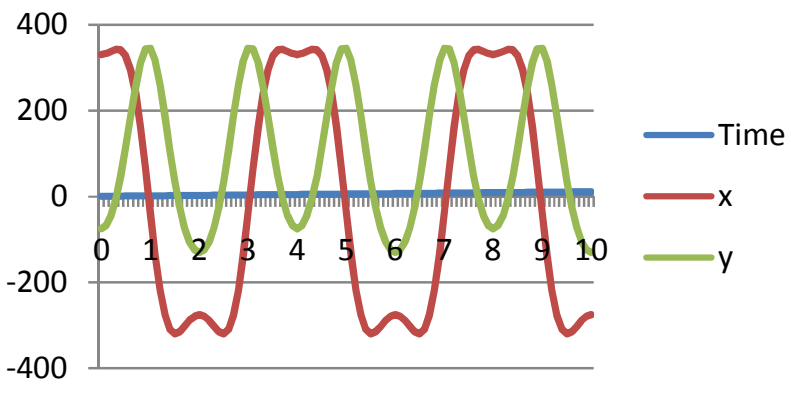

Fig -10: Variation of $\mathrm{X}$ and $\mathrm{Y}$ components of position P3 with time using cosine input

Singularity normally occurs near workspace boundary when both links are fully extended. By increasing the joint range of joint-2, there should not be significant change in workspace boundary but the internal singularities are reduced significantly. There may be existance of unreachable point within the workspace boundary or outside of it due to physical constraints of mechanism. Singularity is a case of infinite acceleration in such cases. The value of $\mathrm{A} \& \mathrm{C}$ are varied from $\pm 10^{\circ}$ to $\pm 90^{\circ}$ for $P_{3}(x, y)$ i.e. workspace boundary determination as plotted in figure 11 .
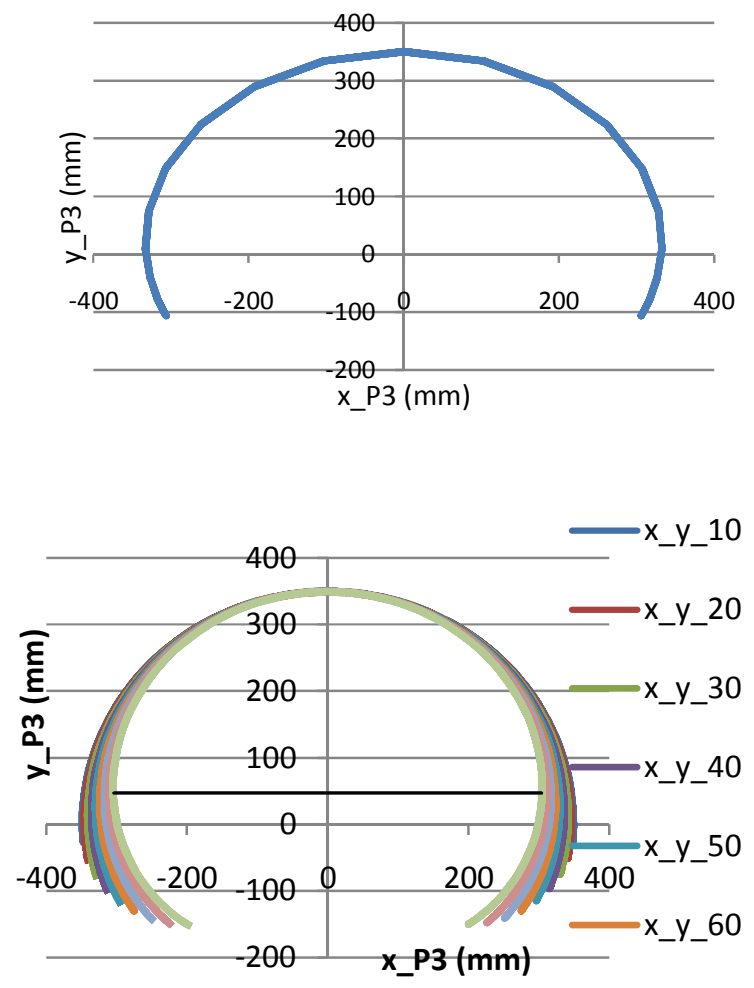

Fig -11: Work space boundary for 2 DOF serial manipulator

\section{CONCLUSIONS}

In this work, the mathematical formulation of complete kinematics and dynamics of two degrees of freedom robotic arm is presented. The simulation of kinematics and dynamics is performed using Pro/Engineer software and results are compared with analytical results. The results are plotted for the performance measurement using condition number and manipubality index. The value of condition number is not well at time of actuation as well as at time of reaching the end of joint limit. The work space boundary represents the limitation of actuations and the space for a placement of work parts. In a robot joint, it is known that friction can relate to temperature, force/torque levels, position, velocity, acceleration, lubricant properties. In this paper, models included nonlinearities and frictions are neglected. It is observed that average variation in the torques computed by Newton's Euler at the both joint axis around 3\% at all possible position compared to Lagrangian dynamics approach using MATLAB and Pro/engineer software.

\section{ACKNOWLEDGEMENTS}

The authors would like to acknowledge support of Sophisticated Instrumentation Centre for Applied Research and Testing (SICART).

\section{REFERENCES}

[1]. Fernando Reyes, Rafael Kelly, Experimental evaluation of model-based controllers on a direct-drive robot arm, Mechatronics, Vol. 11, P.P. 267-282, 2001

[2]. Jolly Shah, S.S.Rattan, B.C.Nakra, Kinematic Analysis of 2-DOF Planer Robot Using Artificial Neural Network, World Academy of Science, Engineering and Technology, Vol. 81, pp. 282-285, 2011

[3]. Denavit, J. \& Hartenberg, R. S., "A kinematic notation for lower-pair mechanisms based on matrices", Journal of Applied Mechanics, Vol., 1, pp. 215-221, 1955

[4]. Tarcisio A.H. Coelho, Liang Yong, Valter F.A. Alves , "Decoupling of dynamic equations by means of adaptive balancing of 2-dof open-loop mechanisms", Mechanism and Machine Theory 39, (2004), 871-881

[5]. B.K. Rout, R.K. Mittal, "Parametric design optimization of 2-DOF R-R planar manipulator- A design of experiment approach", Robotics and Computer-Integrated Manufacturing, 24 (2008) 239-248

[6]. Vigen Arakelian, Jean-Paul Le Baron, Pauline Mottu, "Torque minimization of the 2-DOF serial manipulators based on minimum energy consideration and optimum mass redistribution", Mechatronics, 21 (2011) 310-314

[7]. Ravindra Biradar, M.B.Kiran, "The Dynamics of Fixed Base and Free-Floating Robotic Manipulator", International Journal of Engineering Research \& Technology, Vol. 1 (5), 2012, 1-9 
[8]. M W Spong, On the robust control of robot manipulators. IEEE Transactions on Automatic Control ,Vol. 37(11), P.P. 1782-86, 1992

[9]. A new method for position control of a 2-DOF robot arm using neuro - fuzzy controller, Indian Journal of Science and Technology, Vol. 5(3), 2253-2257, 2012

[10]. Yoshikawa T., "Manipulability of robotic mechanisms", The International Journal of Robotics Research, 4, 1985, No 2, 3-9.

\section{BIOGRAPHIES}

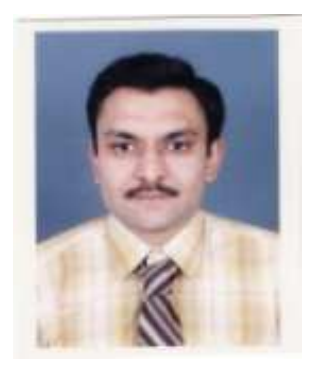

Y.D Patel is working as Associate Professor in Mechanical Engineering department of A D Patel Institute of Technology, New Vallabh Vidyanagar Gujarat.

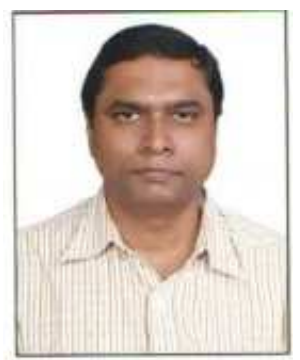

Dr. P.M. George is working as Head of Department of Mechanical Engineering at Birla Vishvakarma Mahavidyalaya, Vallabh Vidyanagar, Gujarat. 